\title{
Evaluate anxiety of adolescents during dental treatment and association with maternal anxiety
}

\author{
Camila B C Fornari (IC), Luale L. Ferreira (PG), Juliana B. Warlet (IC), Ana C Almeida (PG), Rosana F \\ Possobon (PQ)
}

\section{Abstract}

This research checked the association among anxiety related with dentals situations, anxiety reported by adolescent's mothers, family income and education's levels of teenager's mothers, and showed that maternal education and levels of anxiety have significant influences on children's anxiety.

Key words: anxiety, dental fear, adolescents.

\section{Introduction}

The association between fear and dentistry is not natural and inborn to child, but is developed during the socialization and learning process. The developing of anxiety when associated to a dental treatment can be intensified by external influences, like parent's fears. This research investigated the fear of submitting a dental treatment and its association with socioeconomic aspects and maternal anxiety levels between adolescents aged 14 to 16 years old, students of public schools of Piracicaba city on state of São Paulo.

\section{Results and Discussion}

The students' parents receive a copy of TCLE to sign and authorize the student participation, a socioeconomic questionnaire and questions of mensuration instruments of dental fear, the Dental Anxiety Scale 1 . Authorized by parents, adolescents also answered the questions for this dental fear mensuration, Dental Anxiety Scale$^{1}$. Results: The majority of the sample consisted of female adolescents, children of mothers who had completed primary school, whose family earned less than four minimum wages as monthly income, and that lived with five persons in the same house. Most adolescents had lower anxiety grades to the dental treatment. The anxiety grades to the dental treatment was significantly associated to the maternal educational level (OR: 2.6165; IC: 1.2531-5.4629; $\mathrm{p}=0.0146$ ) and maternal level of anxiety (OR: 0.1269; IC: 0,0593-0,2717; $p<0,001$ ).

\section{Conclusions}

We conclude that maternal levels of education and dental anxiety can influence the adolescents' feelings about the dental situation, wherein between mothers with low levels of education and higher level of anxiety there are more adolescents with moderate and extreme anxiety.

\section{Acknowledgement}

We thank PIBIC-CNPq for the studentship concession.

\footnotetext{
${ }^{1}$ Hu LW, Gorenstein C, Fuentes D. Portuguese Version of Corah's dental anxiety scele: Trancultural Adaptation and Reability analysis. 2007;24:467-471.
} 